\title{
Transient Limb Ischemia Alters Serum Protein Expression in Healthy Volunteers: Complement C3 and Vitronectin May Be Involved in Organ Protection Induced by Remote Ischemic Preconditioning
}

\author{
Ting Pang, ${ }^{1}$ Yang Zhao, ${ }^{1}$ Nan-Rong Zhang, ${ }^{1}$ San-Qing Jin, ${ }^{1}$ and San-Qiang Pan ${ }^{2}$ \\ ${ }^{1}$ Department of Anesthesiology, The Sixth Affiliated Hospital, Sun Yat-sen University, No. 26 Yuancunerheng Road, \\ Guangzhou 510655, China \\ ${ }^{2}$ Department of Anatomy, Medical College of Jinan University, No. 601 West Huangpu Avenue, Guangzhou 510632, China
}

Correspondence should be addressed to San-Qing Jin; sanqingjin@hotmail.com and San-Qiang Pan; tpsq@jnu.edu.cn

Received 5 September 2013; Accepted 30 September 2013

Academic Editor: Zhengyuan Xia

Copyright (C) 2013 Ting Pang et al. This is an open access article distributed under the Creative Commons Attribution License, which permits unrestricted use, distribution, and reproduction in any medium, provided the original work is properly cited.

\begin{abstract}
The protective mechanism underlying remote ischemic preconditioning (RIPC) is unclear. This study aims to verify whether the protein expression profile in the serum could be altered by RIPC and to detect potential protein mediators. Transient limb ischemia consisting of three cycles of 5-min ischemia followed by 5 -min reperfusion was performed on sixty healthy volunteers. Serum samples were collected at $30 \mathrm{~min}$ before transient limb ischemia and at 1 hour (h), $3 \mathrm{~h}, 8 \mathrm{~h}, 24 \mathrm{~h}$, and $48 \mathrm{~h}$ after completion of three cycles. Changes in the serum protein profile were analyzed by two-dimensional gel electrophoresis and proteins were identified by MALDI-TOF/TOF mass spectrometry. Fourteen differentially expressed proteins were identified and, respectively, involved in immune system, lipid binding and metabolism, apoptosis, and blood coagulation. Complement C3, vitronectin, and apolipoprotein A-I were further confirmed by western blotting, and the results showed that their contents decreased significantly after transient limb ischemia. It is concluded that transient limb ischemia alters the serum protein expression profile in human being, and that reduction of serum contents of complement $\mathrm{C} 3$ and vitronectin may represent an important part of the mechanism whereby RIPC confers its protection.
\end{abstract}

\section{Introduction}

Ischemic preconditioning (IPC), induced by exposing tissues to transient nonfetal ischemia prior to a prolonged ischemic insult [1], has been proved as a powerful strategy to attenuate ischemia reperfusion (IR) injury. This concept has been developed into remote ischemia preconditioning (RIPC), whereby transient tissue ischemia in one region or organ leads to subsequent protection in distant tissues or organs subjected to potentially lethal ischemia. Przyklenk and colleagues first showed that brief episodes of ischemia of the circumflex artery protect remote myocardium from subsequent sustained left anterior descending artery occlusion in the dog heart [2]. Furthermore, Kharbanda and colleagues conducted a clinical trial in humans and showed that contralateral forearm ischemic preconditioning induced by three cycles of arm ischemia and reperfusion is associated with diminished IR-induced endothelial injury [3]. From then on, this particular protocol has been shown to attenuate myocardial injury in patients with coronary heart disease [47]. Additionally, RIPC has been shown to have an early and late phase of protection [8].

However, the mechanism through which the protective signal is conveyed from the preconditioned limb to the remote organs is unclear, although the neural pathway [8], the humoral pathway [9], and systemic protective response have been proposed. The humoral pathway was suggested by the following studies. Dickson and colleagues showed that coronary effluent obtained from donor hearts subjected to brief preconditioning ischemia could reduce the infarct 
TABLE 1: Healthy volunteers' characteristics*.

\begin{tabular}{lc}
\hline Age (years) & $22(1.8)$ \\
Male & $30(50 \%)$ \\
Mean arterial pressure $(\mathrm{mmHg})$ & $85(9)$ \\
Pulse $\left(\mathrm{bmp}^{\dagger}\right)$ & $75(12)$ \\
Pulse oxygen saturation $(\%)$ & $99(1)$ \\
Body mass index $\left(\mathrm{Kg} / \mathrm{m}^{2}\right)$ & $20.49(2.30)$ \\
\hline
\end{tabular}

${ }^{*}$ Data are mean (SD) or counted number (\%).

${ }^{\dagger}$ bmp: beats per minute.

size in isolated buffer-perfused rabbit hearts [10]. A recent study by Shimizu and co-workers demonstrated that transient limb ischemia released unknown circulating factors which induced a potent protection against myocardial IR injury in Langendorff-perfused hearts and isolated cardiomyocytes in the same species, and this cardioprotection was transferable across species [11]. Our recent study found that the transfusion of plasma collected at late phase of RIPC into homogenic rats could improve the systolic blood pressure recovery during the reperfusion, suggesting that cardioprotective effect of transient limb ischemia was transferable via the plasma [12]. Experimental studies have attempted to identify humoral factors. Using proteomic methods, Lang and colleagues failed to identify a humoral mediator with a molecular weight of more than $8 \mathrm{kDa}$ in rats subjected to remote ischemic preconditioning [13]. Serejo and colleagues speculated that thermolabile hydrophobic substances with molecular weights more than $3.5 \mathrm{kDa}$ were cardioprotective factors in the effluent from preconditioned rat hearts [14]. However, most of the prior studies were performed on animals where circulating substances might vary with species and humoral mediators remained unknown.

We designed and conducted this study to investigate whether serum proteins could be altered by transient limb ischemia in human beings and to explore whether there existed any potential protein mediators in the serum that facilitate the protection induced by RIPC. In this study, transient limb ischemia was conducted in healthy volunteers and the approach of comparative proteomics was applied to identify serum proteins before and after transient limb ischemia. Proteins whose expressions were altered after transient limb ischemia were further studied and some of these proteins were validated by western blotting.

\section{Materials and Methods}

2.1. Subjects. We recruited sixty healthy volunteers and obtained written informed consent from them. Volunteers' characteristics were shown in Table 1 . The study protocol was approved by the Ethics Committee of the Sixth Affiliated Hospital of Sun Yat-Sen University.

2.2. Induction of Transient Limb Ischemia. Transient limb ischemia was achieved by three cycles of ischemia and reperfusion, and each cycle consisted of 5-min ischemia followed by 5-min reperfusion of the nondominant arm.
Ischemia and reperfusion were induced by a $12 \mathrm{~cm}$-wide blood pressure cuff placed on the nondominant upper arm inflated to $200 \mathrm{mmHg}$ for $5 \mathrm{~min}$ and then deflated for $5 \mathrm{~min}$.

2.3. Sample Collection. At $30 \mathrm{~min}$ before transient limb ischemia and at $1 \mathrm{~h}, 3 \mathrm{~h}, 8 \mathrm{~h}, 24 \mathrm{~h}$, and $48 \mathrm{~h}$, respectively, after the the completion of three cycles of transient limb ischemia, blood $(10 \mathrm{~mL})$ was collected from the contralateral arm into tubes and was processed according to a standard operating procedure. The tubes were labeled and transported to the laboratory on ice within $15 \mathrm{~min}$. The blood was centrifuged at $2500 \mathrm{rpm}$ at $4^{\circ} \mathrm{C}$ for $10 \mathrm{~min}$. Serum samples of each volunteer at all the time points were then collected, aliquoted, and stored at $-80^{\circ} \mathrm{C}$. Each serum sample underwent only two freeze/thaw cycles during all the following experimental protocols.

2.4. Two-Dimensional Gel Electrophoresis (2-DE). Samples of 3 volunteers at all the time points were randomly selected from the samples of 60 volunteers to undergo the $2 \mathrm{D}$-gel study. Each serum sample $(1 \mathrm{~mL})$ was processed by using reagents provided by the commercial ProteoMiner Protein Enrichment Kits (Bio-Rad) to decrease high-abundance proteins and to enrich low-abundance proteins. After enrichment, serum was purified by ReadyPrep 2D Cleanup Kit (Bio$\mathrm{Rad})$. Protein concentration was determined by the Bradford assay with the BSA standard (Bio-Rad).

A purified serum sample containing $150 \mu \mathrm{g}$ protein was diluted into $182 \mu \mathrm{L}$ with rehydration buffer $(7 \mathrm{~mol} / \mathrm{L}$ Urea, $2 \mathrm{~mol} / \mathrm{L}$ Thiourea, 2\% CHAPS, 1\% DTT, and 0.2\% Bio-lyte with $\mathrm{pH} 3-10)$ and then loaded to an 11-cm immobilized $\mathrm{pH}$ gradient (IPG) strip (Bio-Rad) followed by passive rehydration for $16 \mathrm{~h}$. Isoelectric focusing (IEF) was performed at $250 \mathrm{~V}$ for $3 \mathrm{~h}$ followed by linear increase of $250-7000 \mathrm{~V}$ for $3 \mathrm{~h}$, then at $8000 \mathrm{~V}$ for $7 \mathrm{~h}$, and finally at $500 \mathrm{~V}$ for $30 \mathrm{~min}$ in the Bio-Rad PROTEAN IEF cell. IPG strips were equilibrated with reducing equilibration buffer $(6 \mathrm{~mol} / \mathrm{L}$ Urea, $50 \mathrm{mmol} / \mathrm{L}$ Tris- $\mathrm{HCl} \mathrm{pH} 8.8,20 \%$ (v/v) glycerol, 2\% (w/v) SDS, and $2 \%(\mathrm{w} / \mathrm{v}) \mathrm{DTT}$ ) for $15 \mathrm{~min}$ followed by equilibration with an alkylating equilibration buffer $(6 \mathrm{~mol} / \mathrm{L}$ Urea, $50 \mathrm{mmol} / \mathrm{L}$ Tris- $\mathrm{HCl} \mathrm{pH} 8.8,20 \%$ (v/v) glycerol, $1 \%(\mathrm{w} / \mathrm{v})$ SDS, and $2.5 \%$ (w/v) IAA) for $15 \mathrm{~min}$. The strips were then placed in the well of $12 \%$ SDS-PAGE gels and sealed with $0.5 \%(\mathrm{w} / \mathrm{v})$ agarose. Separation of the proteins in the second dimension was performed by $12 \%$ SDS polyacrylamide gel electrophoresis. The process began at $120 \mathrm{~V}$ for $30 \mathrm{~min}$ and continued at $150 \mathrm{~V}$ until tracking dye reached the bottom of the gel in a Protean Plus Dodeca cell (Bio-Rad). The gels were then fixed with the fixing solution (10\% methanol plus $7 \%$ acetic acid in water) and stained with SYPRO-Ruby (Bio-Rad) for $16 \mathrm{~h}$ in the dark.

2.5. Protein Identification. Stained gels were scanned by densitometric scanning (Typhoon-9200, Amersham Company, Sweden) and the scanned images were exported into Image Master 2D Elite 5.0 software (Amersham Biosciences, Buckinghamshire, UK) for analysis. Differentially expressed protein spots in the gels, which were the spots expressed more than 1.5-fold differences in expression level as compared 
TABLE 2: Differentially expressed proteins in sera after RIPC compared with that in sera before RIPC.

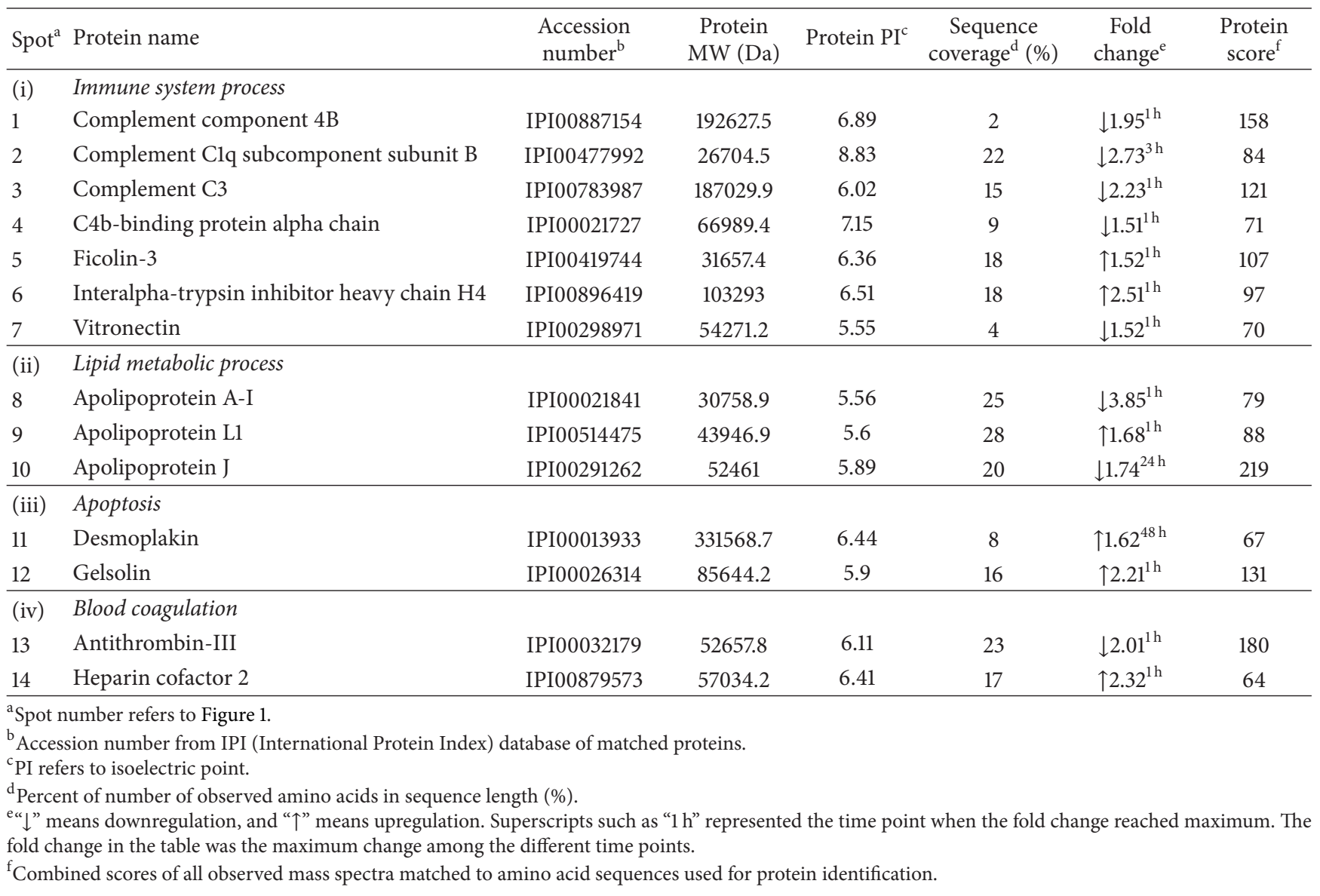

with the samples before transient limb ischemia at any time point after transient limb ischemia, were excised. The excised spots were immediately washed in redistilled water and then washed in $50 \%(\mathrm{v} / \mathrm{v})$ acetonitrile in $100 \mathrm{mmol} / \mathrm{L}$ amine carbonate and then digested with $20 \mu \mathrm{g} / \mathrm{mL}$ trypsin (Roche, Swiss). The extracted peptides were purified by ZipTip pipette tips with $\mu$-C18 Resin (Millipore) and analyzed with tandem time-of-flight 4800 MALDI-TOF/TOF mass spectrometry (Applied Biosystems/MDS Sciex, Toronto, ON, Canada). Protein identification was performed by searching the MS/MS spectra against the international protein index (IPI) database, using a local MASCOT search engine (v2.1, Matrix, London, UK) on a global proteome server (v3.6, Applied Biosystems, Foster City, CA, USA). The database searches were performed using the following parameters: a maximum of 1 missed cleavage, variable modifications of methionine oxidation and cysteine carboxyamidomethylation, and precursor-ion mass tolerance of 0.2 allowed. Homo sapiens were selected as the search species. A protein identification was defined when its peptide had confidence interval value more than $95 \%$.

2.6. Western Blotting. Based on their functional relevance and potential significance with regard to IR injury and organ protection, three proteins of complement C3, vitronectin, and apolipoprotein A-I (apoA-I) were selected to undergo western blotting. Original serum samples from all sixty volunteers were analyzed by western blotting to confirm expressions of the three proteins. Protein concentration was determined by the Bradford assay with the BSA standard (Bio-Rad), and then equal amounts of total protein $(25 \mu \mathrm{g})$ were loaded on $10 \%$ PAGE gels with $5 \%$ stacking gels. The gels underwent electrophoresis at $60 \mathrm{~V}$ for $30 \mathrm{~min}$ and $100 \mathrm{~V}$ for the duration of the run in running buffer $(25 \mathrm{mmol} / \mathrm{L}$ Tris, $192 \mathrm{mmol} / \mathrm{L}$ glycine). The proteins in the gels were then transferred to polyvinylidene difluoride (PVDF) membranes (Millipore) at $100 \mathrm{~V}$ for $100 \mathrm{~min}$ in ice-cold transferring buffer (25 mmol/L Tris, $192 \mathrm{mmol} / \mathrm{L}$ glycine, 20\% (v/v) methanol). After that, PVDF membranes were treated by the MemCode Reversible Protein Stain Kit for PVDF membranes (Pierce, NY) to ensure successful transfer of proteins and to allow for accurate quantitation of protein load. The membranes were blocked in Tris Buffered Saline with Tween (TBST; $170 \mathrm{mmol} / \mathrm{L} \mathrm{NaCl}, 50 \mathrm{mmol} / \mathrm{L}$ Tris, $\mathrm{pH} \mathrm{7.4,0.1 \%} \mathrm{Tween)}$ containing $5 \%$ nonfat milk for $1 \mathrm{~h}$ at room temperature. The membranes were then washed in TBS-T three times (15 min for each time) and incubated with antibodies for $10 \mathrm{~h}$ to $12 \mathrm{~h}$ at $4^{\circ} \mathrm{C}$. The dilution ratio of the antibodies for target proteins was: complement C3 1:500 (Santa, sc52629), vitronectin 1:500 (R\&D, Clone 342603), and apoAI 1:500 (Abcam, ab52945). Membranes were then washed three times (15 min for each time) in TBS-T. The secondary 


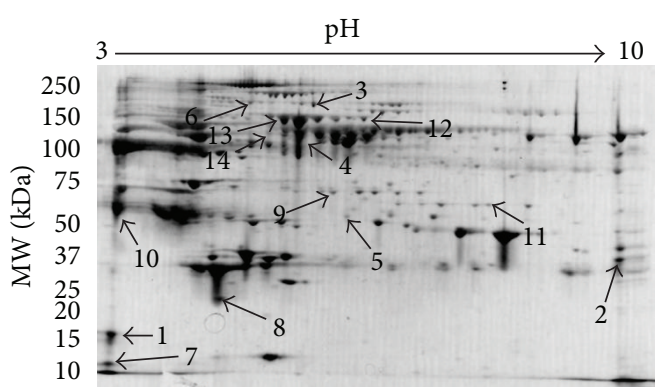

(a)

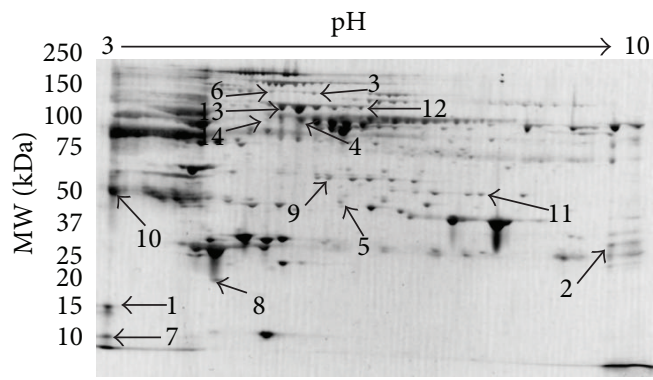

(c)

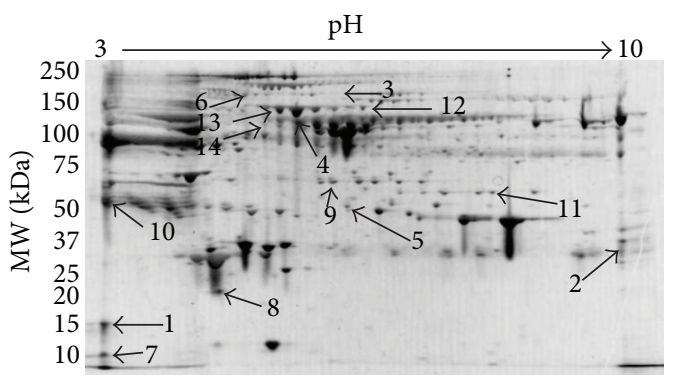

(e)

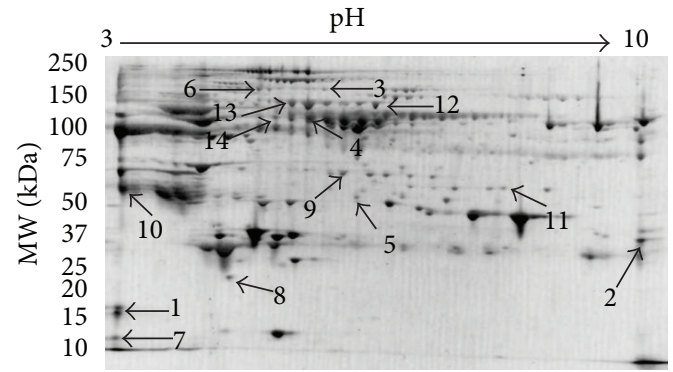

(b)

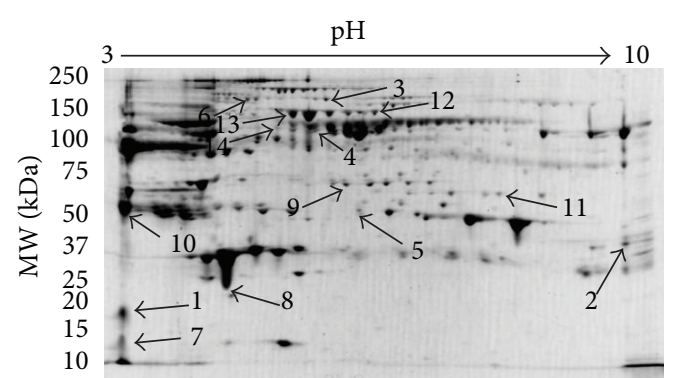

(d)

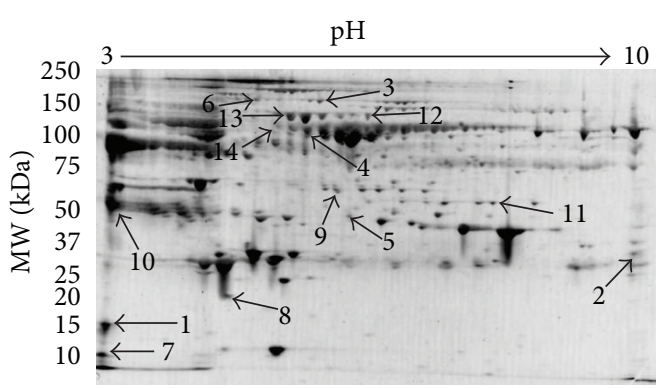

(f)

FIGURE 1: Representative images of SYPRO-Ruby-stained 2-DE gels. Representative images of SYPRO-Ruby-stained 2-DE gels at various time points ((a) before transient limb ischemia, (b) $1 \mathrm{~h}$ after transient limb ischemia, (c) $3 \mathrm{~h}$ after transient limb ischemia, (d) $8 \mathrm{~h}$ after transient limb ischemia, (e) $24 \mathrm{~h}$ after transient limb ischemia, and (f) $48 \mathrm{~h}$ after transient limb ischemia). The high-abundant proteins such as albumin and immunoglobulins were depleted from serum using the multiple-affinity column, as described in Section 2. Zoomed areas highlight typical spots (arrows) of the fourteen differentially expressed proteins. Changes in these spots' intensity among different time points are clearly visible. The spot numbers refer to proteins summarized in Table 2.

antibody for complement $\mathrm{C} 3$ and vitronectin was donkey anti-mouse IgG-HRP 1:2000 (Santa, sc-2318) and for apoAI was donkey anti-rabbit IgG-HRP 1:2000 (Santa, sc-2317). Membranes were incubated with secondary antibody for $1 \mathrm{~h}$ at $26^{\circ} \mathrm{C}$ and then washed three times in TBS-T ( $15 \mathrm{~min}$ for each time). Protein blots in the membranes were visualized by enhanced chemiluminescence (ECL) and then exposed to X-ray films (Kodak, USA). Films were scanned into digital images. The primary densities of the band of complement $\mathrm{C} 3$, vitronectin at $75 \mathrm{kDa}$, vitronectin at $65 \mathrm{kDa}$, and apoA-I were measured by Quantity One 4.62 (Bio-Rad), respectively. Protein expression levels were presented as relative density. The primary band densities at each time point after transient limb ischemia were divided by the band densities before transient limb ischemia (base line) in the same gel. Then relative densities before transient limb ischemia (base) were 1 according to the normalization in all conditions.
2.7. Statistical Analysis. Quantitative data were analyzed with statistical package SPSS 16.0 (Chicago, IL). Data were presented as mean \pm standard deviation of the mean. Repeatedmeasures analysis of variance (RMANOVA) was used for serial measurements. Statistical significances were evaluated at a two-tailed significance level of 0.05 . This trial was registered with ClinicalTrials.gov, no. NCT01118000.

\section{Results}

3.1. Serum Proteomic Profile. Differentially expressed protein spots in the gels were identified as fourteen different proteins by MALDI-TOF/TOF mass spectrometry and database search (Figure 1). A typical MALDIMS spectrum and MS/MS map were shown in Figure 2. The fourteen identified proteins were classified based on gene ontology (GO) annotations (Table 2). 


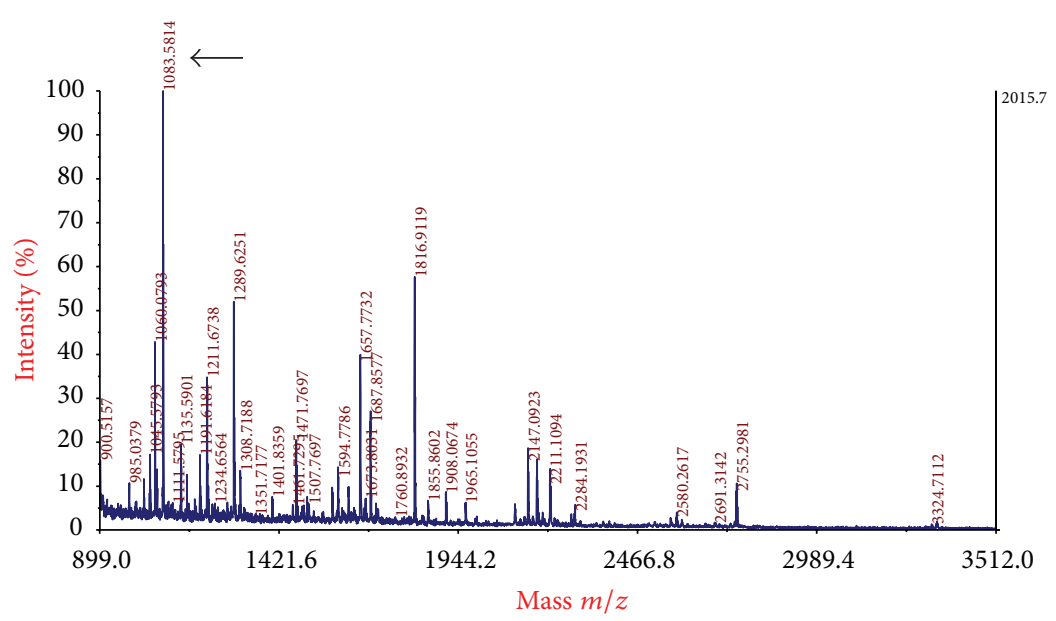

(a)

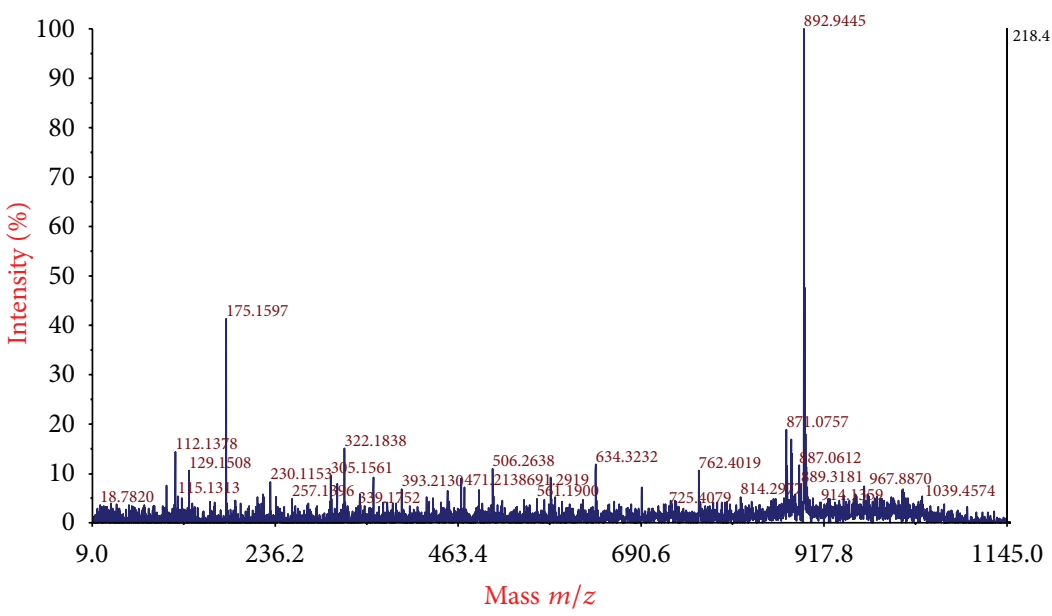

(b)

Figure 2: Peptide mass fingerprinting spectrum and a typical MS/MS map of complement C3. (a) Peptide mass fingerprinting spectrum of complement C3. The arrow indicates the peptide detected at $\mathrm{m} / z$ 1083.5814. (b) A typical MS/MS map of complement C3. The sequence of precursor at $m / z 1083.5814$ (arrow in (a)) was analyzed in this map.

Among these fourteen proteins, seven proteins were related to immune response processes, including complement component $4 \mathrm{~B}$, complement $\mathrm{Clq}$ subcomponent subunit $\mathrm{B}$, complement $\mathrm{C} 3$, C4b-binding protein alpha chain and ficolin-3 in complement pathway, vitronectin in immune response, and interalpha-trypsin inhibitor heavy chain $\mathrm{H} 4$ in acute phase response. Among the altered proteins, ficolin-3 and interalpha-trypsin inhibitor heavy chain $\mathrm{H} 4$ were upregulated, while the other proteins were downregulated. Besides, three proteins involved in lipid metabolic process were affected, namely, apoA-I and apolipoprotein J downregulated and apolipoprotein L1 upregulated. These proteins were also related to immune response. Then, two proteins involved in cell apoptosis were all upregulated, including desmoplakin and gelsolin. Finally, two proteins related to blood coagulation were also affected, antithrombin-III downregulated, and heparin cofactor 2 upregulated.

3.2. Changes of Complement C3, Vitronectin, and ApoA-I Validated by Western Blotting Analysis. The contents of the three proteins (complement C3, vitronectin, and apoA-I) in the volunteers' sera $(n=60)$ were decreased after transient limb ischemia. The decrease was significant at most of the time points as compared with the values before transient limb ischemia (Figure 3).

Baseline relative density of complement $\mathrm{C} 3$ was defined as 1 . The reduction of complement $\mathrm{C} 3$ was significant at $1 \mathrm{~h}$ $(0.84 \pm 0.37$ at $1 \mathrm{~h}$ versus $1 ; P=0.002), 3 \mathrm{~h}(0.86 \pm 0.54$ versus $1 ; P=0.049), 8 \mathrm{~h}(0.76 \pm 0.48$ versus $1 ; P=0.000)$, and $24 \mathrm{~h}$ $(0.78 \pm 0.49$ versus $1 ; P=0.001)$ after transient limb ischemia but not at $48 \mathrm{~h}(0.88 \pm 0.62$ versus $1 ; P=0.140$, Figure $3(\mathrm{~b}))$ after transient limb ischemia.

Baseline relative density of vitronectin $(75 \mathrm{KDa})$ was defined as 1 . The reduction of vitronectin $(75 \mathrm{KDa})$ was significant at $8 \mathrm{~h}(0.87 \pm 0.36$ at $8 \mathrm{~h}$ versus $1 ; P=0.013), 24 \mathrm{~h}$ $(0.83 \pm 0.43$ versus $1 ; P=0.004)$, and $48 \mathrm{~h}(0.87 \pm 0.40$ versus $1 ; P=0.023)$ after transient limb ischemia but not at $1 \mathrm{~h}$ $(0.98 \pm 0.24$ versus $1 ; P=0.604)$ and $3 \mathrm{~h}(0.96 \pm 0.35$ versus 1 ; $P=0.409$; Figure 3(c)) after transient limb ischemia. 


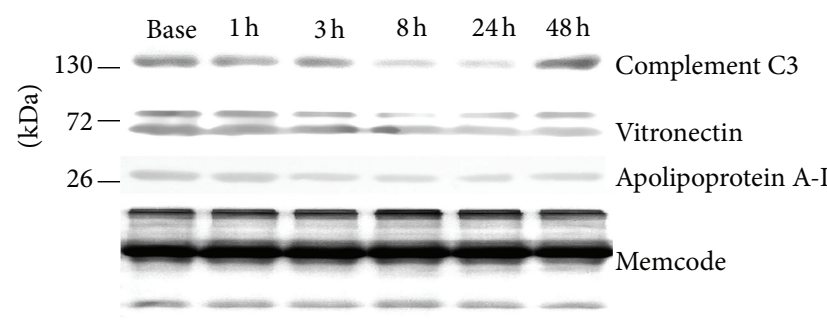

(a)

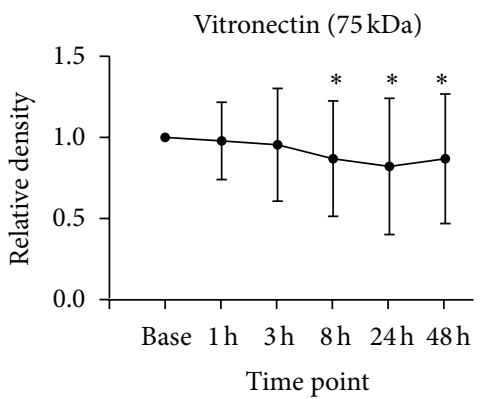

(c)

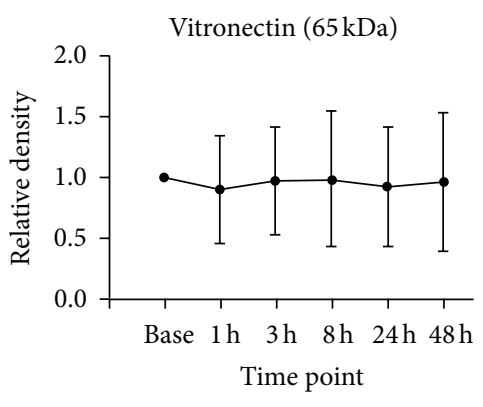

(d)

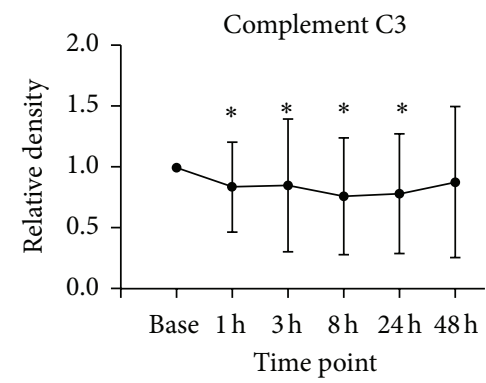

(b)

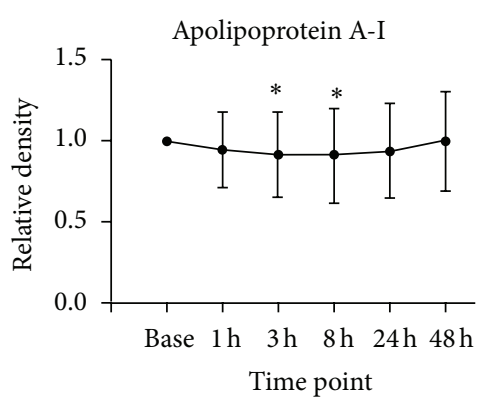

(e)

FIGURE 3: Western blotting data of complement C3, vitronectin, and apoA-I. The results were presented as mean \pm SD. Error bars were SD. Repeated-measures analysis of variances was performed to evaluate statistical significance. ${ }^{*} P<0.05$. (a) Representative western blotting images of serum samples from healthy volunteers obtained prior to transient limb ischemia (base) and at various time points $(1 \mathrm{~h}, 3 \mathrm{~h}, 8 \mathrm{~h}$, $24 \mathrm{~h}$, and $48 \mathrm{~h}$ ) thereafter. Memcode was shown to demonstrate equal protein loading. (b) Changes in the expression of complement C3 after transient limb ischemia compared with that before transient limb ischemia $(n=60)$. (c) Changes in the expression of vitronectin at $75 \mathrm{kDa}$ after transient limb ischemia compared with that before transient limb ischemia $(n=60)$. (d) Changes in the expression of vitronectin at $65 \mathrm{kDa}$ after transient limb ischemia compared with that before transient limb ischemia $(n=60)$. (e) Changes in the expression of apoA-I after transient limb ischemia compared with that before transient limb ischemia $(n=60)$.

Baseline relative density of vitronectin $(65 \mathrm{KDa})$ was defined as 1 . The reduction of vitronectin $(65 \mathrm{KDa})$ was not significant at $1 \mathrm{~h}(0.90 \pm 0.44$ versus $1 ; P=0.123), 3 \mathrm{~h}$ $(0.97 \pm 0.44$ versus $1 ; P=0.646), 8 \mathrm{~h}(0.98 \pm 0.56$ versus 1 ; $P=0.789), 24 \mathrm{~h}(0.92 \pm 0.49$ versus $1 ; P=0.261)$, and $48 \mathrm{~h}$ $(0.96 \pm 0.56$ versus $1 ; P=0.646)$ after transient limb ischemia (Figure 3(d)).

Baseline relative density of apoA-I was defined as 1 . The reduction of apoA-I was significant at $3 \mathrm{~h}(0.92 \pm 0.26$ at $3 \mathrm{~h}$ versus $1 ; P=0.016)$ and $8 \mathrm{~h}(0.91 \pm 0.29$ versus $1 ; P=0.026)$ after transient limb ischemia but not at $1 \mathrm{~h}(0.95 \pm 0.23$ versus $1 ; P=0.119), 24 \mathrm{~h}(0.94 \pm 0.29$ versus $1 ; P=0.11)$ and $48 \mathrm{~h}$ $(1.00 \pm 0.30$ versus $1 ; P=0.905)$ after transient limb ischemia (Figure 3(e)).

\section{Discussion}

There were hardly any studies conducted amongst healthy volunteers in order to detect clinically relevant protein mediators that facilitate the protective effects of RIPC. Isolated buffer-perfused animal hearts in vitro and animal models in vivo have been extensively used for investigating the protective effect and mechanism of RIPC. Although these models have been shown to be reproducible and efficient, isolated hearts could not reflect the effects of nervous and circulatory system in the whole body, and animal disease models cannot represent the complex human clinical setting very well. Therefore, conducting a controlled human study is a crucial translational step from bench to bedside. A recent human study by Hepponstall et al. found that the RIPC stimulus modified the plasma protein content in blood, but this study enrolled only five healthy volunteers [15].

In this study, we compared serum proteins profiles after transient limb ischemia with that before transient limb ischemia in healthy volunteers by a proteomic approach and showed that there existed changes of serum proteins induced by transient limb ischemia. The changed proteins were mainly involved in the inflammatory system and also involved in the lipid metabolic system, cell apoptosis, and coagulation system.

In the 2-DE results of our study, we observed that complement component $4 \mathrm{~B}$, complement $\mathrm{Clq}$ subcomponent subunit $\mathrm{B}, \mathrm{C} 4 \mathrm{~b}$-binding protein alpha chain, and complement C3 were all decreased after transient limb ischemia.

Furthermore, we confirmed the changes of three proteins of complement $\mathrm{C} 3$, vitronectin $(75 \mathrm{KDa})$, and apoAI after transient limb ischemia by western blotting. The downregulation of complement $\mathrm{C} 3$ could persist for one day or perhaps even longer, the content of vitronectin $(75 \mathrm{KDa})$ decreased significantly at $8 \mathrm{~h}, 24 \mathrm{~h}$, and $48 \mathrm{~h}$ after transient limb ischemia, and the content of apoA-I decreased significantly at $3 \mathrm{~h}$ and $8 \mathrm{~h}$ after transient limb ischemia. 
The pathway through which RIPC protects organs is unclear, but three possible mechanisms have been suggested [16]. The neural hypothesis proposed that the remote preconditioned organs could release endogenous substances such as adenosine [17], bradykinin [18], or calcitonin generelated peptide [19] which activated afferent neural pathway terminating at the heart to confer myocardial protection. On the other hand, the humoral hypothesis thought that these released endogenous substances or some other humoral factors were carried to the heart in the blood stream and recognized specific receptors in the myocardium to activate intracellular pathways of myocardial protection. Finally, RIPC could suppress inflammation and apoptosis, which was called systemic protective response [20]. Our results showed the changes of serum proteins after transient limb ischemia and these proteins mainly involved in inflammatory response, which may support the second and third hypothesis above mentioned.

The complement cascade has been shown to be a key mediator of IR injury $[21,22]$. Inhibition of the complement system can improve the outcome of IR injury [23, 24]. In a rabbit model, Tanhehco and co-workers observed that ischemic and chemical preconditioning inhibited the upregulation of complement C1q, C1r, C3, C8, and C9 mRNA expression and the complement $\mathrm{C} 3$ and membrane attack complex protein expression caused by IR injury both in vivo and in isolated heart in rabbits $[25,26]$.

Complement C3 is the central molecule of the complement system, at which the classical, lectin, and alternative pathways converge. Complement C3 is also associated with myocardial infarction, and it is more significant than any other traditional risk factors [27]. We selected complement C3 for further validation by western blotting and showed that the complement C3 expression in human serum significantly decreased from $1 \mathrm{~h}$ to $24 \mathrm{~h}$ after transient limb ischemia. A study by Zheng and colleagues demonstrated that siRNA solution containing siRNAs targeting tumor necrosis factor $\alpha$, complement C3, and Fas genes could decrease cardiac IR injury, protect cardiac function, and prolong graft survival in heart transplantation [28]. Mocco and co-workers used mice deficient in selected complement proteins (C1q, C3, and C5) to evaluate which complement subcomponents contribute to cerebral IR injury and demonstrated that only C3-/- mice experienced significant neuroprotection [29].

Vitronectin is a multifunctional glycoprotein present in plasma, extracellular matrix, and blood platelets. It is found in two molecular forms in human blood, which are a single chain $(75 \mathrm{kDa})$ and a clipped form of two chains (65 and $10 \mathrm{kDa}$ ) [30]. In our study, we also observed the vitronectin fragment located at $\sim 10 \mathrm{kDa}$ by $2-\mathrm{DE}$ and the vitronectin doublet located at $65 \sim 75 \mathrm{kDa}$ by western blotting. Vitronectin has been implicated as a regulator of many diverse physiological processes [31]. Ekmekci and colleagues showed that plasma vitronectin levels in patients with coronary artery diseases were significantly increased and positively correlated with the extent of diseases [32]. Yamani and colleagues observed that myocardial ischemic injury after cardiac transplantation was associated with upregulation of vitronectin receptor (integrin $\alpha \mathrm{V} \beta 3$ ) [33]. Using data from a randomized, placebocontrolled trial of abciximab in patients undergoing percutaneous coronary intervention, Derer and co-workers found that serum concentration of vitronectin was an independent risk factor for adverse cardiovascular events [34].

ApoA-I is the major protein of high-density lipoprotein. Besides its role in cholesterol metabolism, it possesses antiatherosclerotic, antioxidant, anti-inflammatory, and antithrombotic activities $[35,36]$. A recent study by Shi and $\mathrm{Wu}$ showed that apoA-I reduced IR-induced inflammatory responses, decreased renal microscopic damage, and improved renal function [37]. Our results may implicate that apoA-I is not involved in the protective mechanism of RIPC.

This study was designed as a self-control study to confirm whether the composition of serum proteins was changed after transient limb ischemia in human beings. Time points for blood sample collection were selected in consideration of early and late phase of protection induced by RIPC. The early phase lasts for up to $3 \mathrm{~h}$ after ischemic preconditioning, whereas the late phase starts at $12-24 \mathrm{~h}$ after ischemic preconditioning [8]. Our study suggested that reduction of complement C3 and vitronectin expression may be involved in the mechanism by which preconditioning salvage tissues or organs subsequently subjected to IR, although they are likely to reflect changes induced by the preconditioning mediators. Further study is needed to find by which way these proteins are altered by transient limb ischemia and confirm whether these altered proteins actually protect organs.

It should be noted that it is very complicated to elucidate the mechanism of RIPC. Nevertheless, this study just finds some changes of serum proteins at limited time points which should serve to facilitate future extensive work aimed to elucidate the RIPC protective mechanism.

\section{Conflict of Interests}

All authors declared no conflicts of interests.

\section{Authors' Contribution}

Ting Pang, Yang Zhao, and Nan-Rong Zhang contributed equally to this study. San-Qing Jin and San-Qiang Pan designed the experiment, and San-Qing Jin supervised the whole process of the study and revised the paper draft. SanQiang Pan helped analyzing the data. Ting Pang and Yang Zhao did the experiment (including sera collection, 2-DE, and western blotting), analyzed the data, and wrote the paper draft. Nan-Rong Zhang recruited volunteers and performed transient limb ischemia on volunteers. All authors have seen and approved the final version of this paper.

\section{Acknowledgments}

The authors thank the Natural Science Foundation from Department of Science and Technology of Guangdong province for its support (no. 07001664). The authors thank Hong-Bin Feng, Yan Zhou, and Dan Hu at Department of Anesthesiology in the Sixth Affiliated Hospital of Sun Yat-Sen 
University for recruiting volunteers and collecting blood and Su-Mei Li and Hong-Hai Yuan at Department of Anatomy in Medical College of Jinan University for their assistance in western blotting and protein identification.

\section{References}

[1] C. E. Murry, R. B. Jennings, and K. A. Reimer, "Preconditioning with ischemia: a delay of lethal cell injury in ischemic myocardium," Circulation, vol. 74, no. 5, pp. 1124-1136, 1986.

[2] K. Przyklenk, B. Bauer, M. Ovize, R. A. Kloner, and P. Whittaker, "Regional ischemic 'preconditioning' protects remote virgin myocardium from subsequent sustained coronary occlusion," Circulation, vol. 87, no. 3, pp. 893-899, 1993.

[3] R. K. Kharbanda, U. M. Mortensen, P. A. White et al., "Transient limb ischemia induces remote ischemic preconditioning in vivo," Circulation, vol. 106, no. 23, pp. 2881-2883, 2002.

[4] D. J. Hausenloy, P. K. Mwamure, V. Venugopal et al., "Effect of remote ischaemic preconditioning on myocardial injury in patients undergoing coronary artery bypass graft surgery: a randomised controlled trial," The Lancet, vol. 370, no. 9587, pp. 575-579, 2007.

[5] S. P. Hoole, P. M. Heck, L. Sharples et al., "Cardiac remote ischemic preconditioning in coronary stenting (CRISP stent) study. A prospective, randomized control trial," Circulation, vol. 119, no. 6, pp. 820-827, 2009.

[6] I. Rentoukas, G. Giannopoulos, A. Kaoukis et al., "Cardioprotective role of remote ischemic periconditioning in primary percutaneous coronary intervention. enhancement by opioid action," JACC: Cardiovascular Interventions, vol. 3, no. 1, pp. 49$55,2010$.

[7] H. E. Bøtker, R. Kharbanda, M. R. Schmidt et al., "Remote ischaemic conditioning before hospital admission, as a complement to angioplasty, and effect on myocardial salvage in patients with acute myocardial infarction: a randomised trial," The Lancet, vol. 375, no. 9716, pp. 727-734, 2010.

[8] S. P. Loukogeorgakis, A. T. Panagiotidou, M. W. Broadhead, A. Donald, J. E. Deanfield, and R. J. MacAllister, "Remote ischemic preconditioning provides early and late protection against endothelial ischemia-reperfusion injury in humans: role of the autonomic nervous system," Journal of the American College of Cardiology, vol. 46, no. 3, pp. 450-456, 2005.

[9] E. W. Dickson, C. P. Reinhardt, F. P. Renzi, R. C. Becker, W. A. Porcaro, and S. O. Heard, "Ischemic preconditioning may be transferable via whole blood transfusion: preliminary evidence," Journal of Thrombosis and Thrombolysis, vol. 8, no. 2, pp. 123129, 1999.

[10] E. W. Dickson, M. Lorbar, W. A. Porcaro et al., "Rabbit heart can be "preconditioned" via transfer of coronary effluent," The American Journal of Physiology-Heart and Circulatory Physiology, vol. 277, no. 6, pp. H2451-H2457, 1999.

[11] M. Shimizu, M. Tropak, R. J. Diaz et al., "Transient limb ischaemia remotely preconditions through a humoral mechanism acting directly on the myocardium: evidence suggesting cross-species protection," Clinical Science, vol. 117, no. 5, pp. 191200, 2009.

[12] Y. Zhao, Z. N. Zheng, S. Q. Jin, and H. M. Liang, "Effects of plasma collected 48 hours after transient limb ischemia on blood pressure recovery in homogenic rats after myocardial ischemia reperfusion in vivo," Chinese Medical Journal, vol. 126, no. 15, pp. 2894-2899, 2013.
[13] S. C. Lang, A. Elsässer, C. Scheler et al., "Myocardial preconditioning and remote renal preconditioning-identifying a protective factor using proteomic methods?" Basic Research in Cardiology, vol. 101, no. 2, pp. 149-158, 2006.

[14] F. C. Serejo, L. F. Rodrigues Jr., K. C. da Silva Tavares, A. C. C. de Carvalho, and J. H. M. Nascimento, "Cardioprotective properties of humoral factors released from rat hearts subject to ischemic preconditioning," Journal of Cardiovascular Pharmacology, vol. 49, no. 4, pp. 214-220, 2007.

[15] M. Hepponstall, V. Ignjatovic, S. Binos et al., "Remote ischemic preconditioning (RIPC) modifies plasma proteome in humans," PLoS ONE, vol. 7, no. 11, Article ID e48284, 2012.

[16] D. J. Hausenloy and D. M. Yellon, "Remote ischaemic preconditioning: underlying mechanisms and clinical application," Cardiovascular Research, vol. 79, no. 3, pp. 377-386, 2008.

[17] T. J. Pell, G. F. Baxter, D. M. Yellon, and G. M. Drew, "Renal ischemia preconditions myocardium: role of adenosine receptors and ATP-sensitive potassium channels," The American Journal of Physiology-Heart and Circulatory Physiology, vol. 275, no. 5, pp. H1542-H1547, 1998.

[18] R. G. Schoemaker and C. L. van Heijningen, "Bradykinin mediates cardiac preconditioning at a distance," The American Journal of Physiology-Heart and Circulatory Physiology, vol. 278, no. 5, pp. H1571-H1576, 2000.

[19] Z. L. Tang, W. Dai, Y. J. Li, and H. W. Deng, "Involvement of capsaicin-sensitive sensory nerves in early and delayed cardioprotection induced by a brief ischaemia of the small intestine," Naunyn-Schmiedeberg's Archives of Pharmacology, vol. 359, pp. 243-247, 1999.

[20] I. E. Konstantinov, S. Arab, R. K. Kharbanda et al., "The remote ischemic preconditioning stimulus modifies inflammatory gene expression in humans," Physiological Genomics, vol. 19, pp. 143150, 2005.

[21] M. Ikai, M. Itoh, T. Joh, Y. Yokoyama, N. Okada, and H. Okada, "Complement plays an essential role in shock following intestinal ischaemia in rats," Clinical and Experimental Immunology, vol. 106, no. 1, pp. 156-159, 1996.

[22] M. Pemberton, G. L. Anderson, V. Vetvicka, D. E. Justus, and G. D. Ross, "Microvascular effects of complement blockade with soluble recombinant CR1 on ischemia/reperfusion injury of skeletal muscle," The Journal of Immunology, vol. 150, no. 11, pp. 5104-5113, 1993.

[23] G. A. Toomayan, L. E. Chen, H. X. Jiang et al., "C1-esterase inhibitor and a novel peptide inhibitor improve contractile function in reperfused skeletal muscle," Microsurgery, vol. 23, no. 6, pp. 561-567, 2003.

[24] B. de Vries, R. A. Matthijsen, T. G. A. M. Wolfs, A. A. J. H. M. van Bijnen, P. Heeringa, and W. A. Buurman, "Inhibition of complement factor C5 protects against renal ischemia-reperfusion injury: inhibition of late apoptosis and inflammation," Transplantation, vol. 75, no. 3, pp. 375-382, 2003.

[25] E. J. Tanhehco, K. Yasojima, P. L. McGeer et al., "Preconditioning reduces tissue complement gene expression in the rabbit isolated heart," The American Journal of Physiology-Heart and Circulatory Physiology, vol. 277, no. 6, pp. H2373-H2380, 1999.

[26] E. J. Tanhehco, K. Yasojima, P. L. McGeer, E. G. McGeer, and B. R. Lucchesi, "Preconditioning reduces myocardial complement gene expression in vivo," The American Journal of PhysiologyHeart and Circulatory Physiology, vol. 279, no. 3, pp. H1157H1165, 2000.

[27] A. Muscari, G. Massarelli, L. Bastagli et al., "Relationship of serum C3 to fasting insulin, risk factors and previous ischaemic 
events in middle-aged men," European Heart Journal, vol. 21, no. 13, pp. 1081-1090, 2000.

[28] X. Zheng, D. Lian, A. Wong et al., "Novel small interfering RNA-containing solution protecting donor organs in heart transplantation," Circulation, vol. 120, no. 12, pp. 1099-1107, 2009.

[29] J. Mocco, W. J. Mack, A. F. Ducruet et al., "Complement component C3 mediates inflammatory injury following focal cerebral ischemia," Circulation Research, vol. 99, no. 2, pp. 209-217, 2006.

[30] D. Seiffert and R. R. Schleef, "Two functionally distinct pools of vitronectin $(\mathrm{Vn})$ in the blood circulation: Identification of a heparin-binding competent population of Vn within platelet $\alpha$ granules," Blood, vol. 88, no. 2, pp. 552-560, 1996.

[31] P. Zhuang, M. N. Blackburn, and C. B. Peterson, "Characterization of the denaturation and renaturation of human plasma vitronectin I. Biophysical characterization of protein unfolding and multimerization," Journal of Biological Chemistry, vol. 271, no. 24, pp. 14323-14332, 1996.

[32] H. Ekmekci, H. Sonmez, O. B. Ekmekci, Z. Ozturk, N. Domanic, and E. Kokoglu, "Plasma vitronectin levels in patients with coronary atherosclerosis are increased and correlate with extent of disease," Journal of Thrombosis and Thrombolysis, vol. 14, no. 3, pp. 221-225, 2002.

[33] M. H. Yamani, E. M. Tuzcu, R. C. Starling et al., "Myocardial ischemic injury after heart transplantation is associated with upregulation of vitronectin receptor $(\alpha(\mathrm{v}) \beta 3)$, activation of the matrix metalloproteinase induction system, and subsequent development of coronary vasculopathy," Circulation, vol. 105, no. 16, pp. 1955-1961, 2002.

[34] W. Derer, E. S. Barnathan, E. Safak et al., "Vitronectin concentrations predict risk in patients undergoing coronary stenting," Circulation: Cardiovascular Interventions, vol. 2, no. 1, pp. 14-19, 2009.

[35] P. J. Barter, S. Nicholls, K. A. Rye, G. M. Anantharamaiah, M. Navab, and A. M. Fogelman, "Antiinflammatory properties of HDL," Circulation Research, vol. 95, no. 8, pp. 764-772, 2004.

[36] C. Mineo, H. Deguchi, J. H. Griffin, and P. W. Shaul, "Endothelial and antithrombotic actions of HDL," Circulation Research, vol. 98, no. 11, pp. 1352-1364, 2006.

[37] N. Shi and M. P. Wu, "Apolipoprotein A-I attenuates renal ischemia/reperfusion injury in rats," Journal of Biomedical Science, vol. 15, no. 5, pp. 577-583, 2008. 


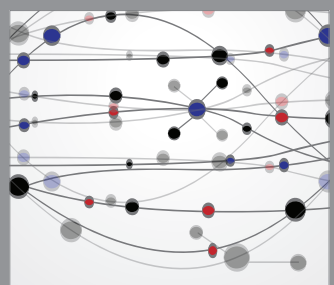

The Scientific World Journal
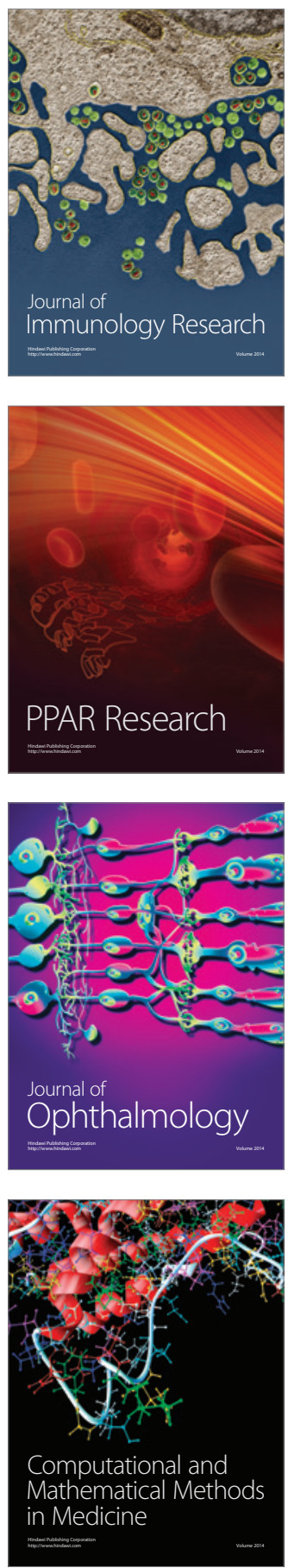

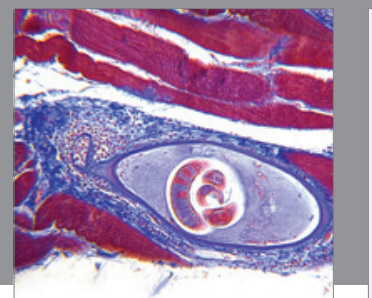

Gastroenterology

Research and Practice
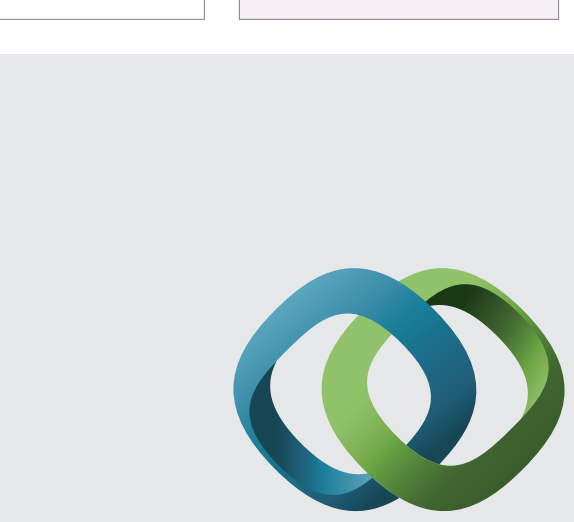

\section{Hindawi}

Submit your manuscripts at

http://www.hindawi.com
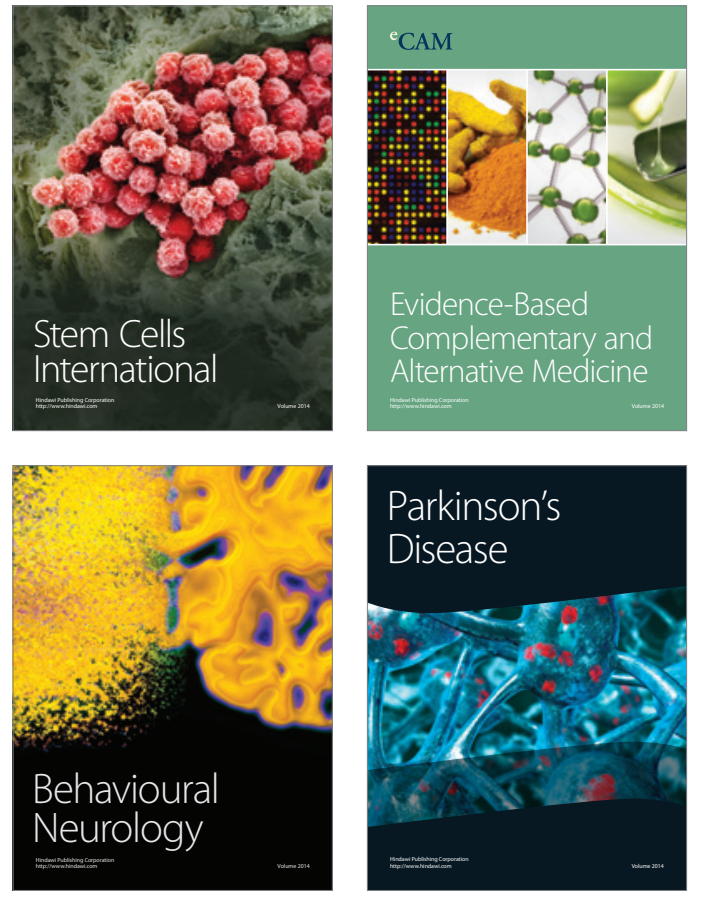
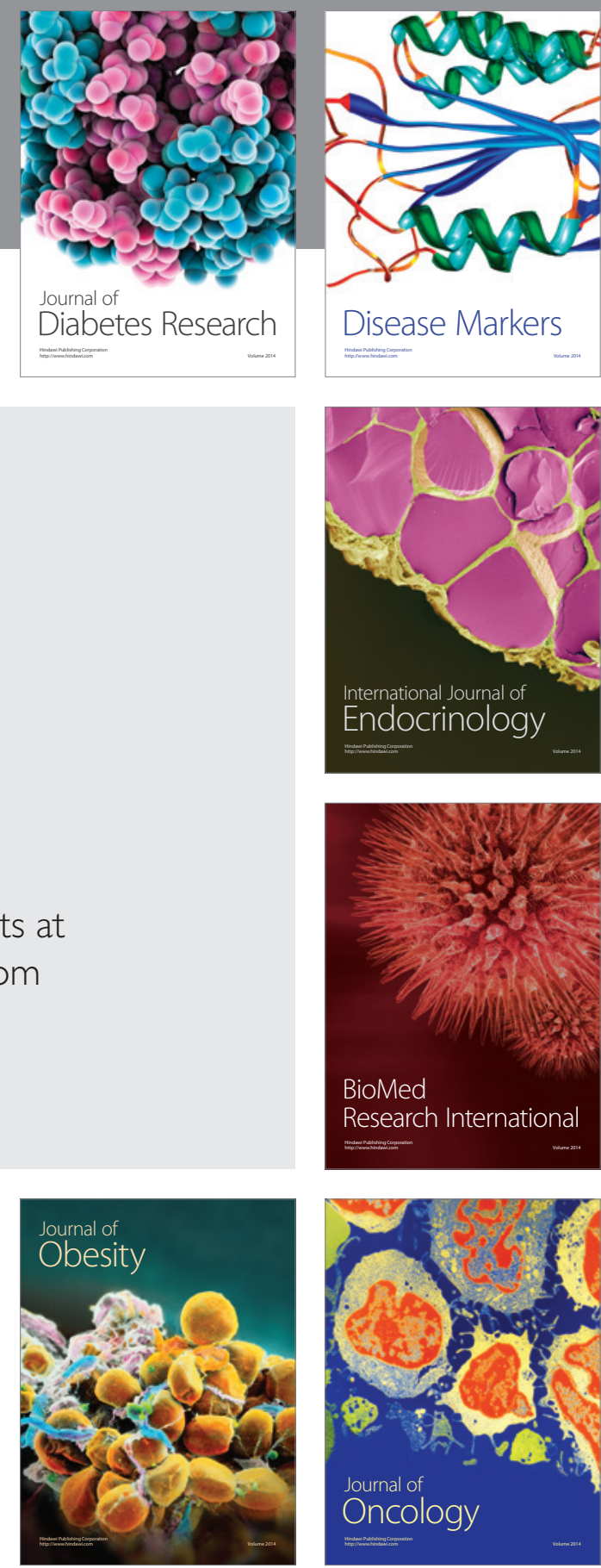

Disease Markers
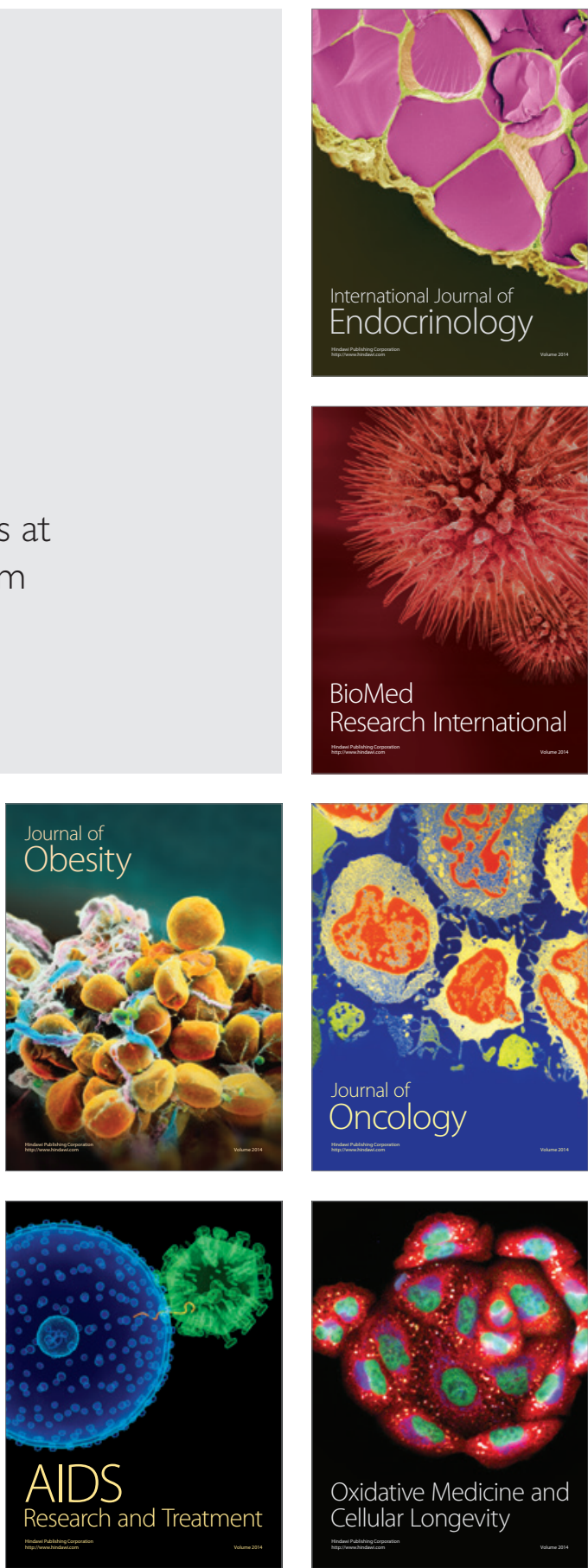